\title{
Idoso institucionalizado: 0 que sente, percebe e deseja?
}

\author{
Hercules de Oliveira Carmo*, Janaina Roma Azen Rangel*, \\ Nicoli Aparecida do Prado Ribeiro", Claudia Lysia de Oliveira Araújo**
}

\section{Resumo}

Este trabalho trata de uma realidade que vem surgindo: o idoso, perante o processo de institucionalização que passa por várias etapas, deixa sua casa e passa a conviver com regras, um novo lugar e pessoas desconhecidas. O objetivo deste estudo foi identificar o que esse idoso sente, percebe e deseja diante de todas essas mudanças, evidenciando os sentimentos que o envolvem. Observa-se um predomínio de sujeitos do sexo feminino, entre 70 a 80 anos, solteiros e investiga-se os motivos que os levaram a ficar sozinhos. O presente estudo traz relatos dos idosos sobre o processo de institucionalização, o que permite tecer algumas considerações. Apesar de tanta tecnologia e evolução, ainda existe um grupo de pessoas que, sem apoio da sociedade e da família, quer viver, ser feliz, tem sentimentos, desejos, percebe que seu espaço diminui e, sem alternativa, vê restar para si a institucionalização.

Palavras-chave: Idoso. Instituição de Longa Permanência para Idosos. Sentimento.

\section{Introdução}

Este trabalho trata de uma realidade sobre a qual, muitas vezes, a sociedade e a família não costumam refletir. Éramos um país formado por jovens, pois, de acordo com dados do IBGE, em 1940, apenas $4 \%$ da população tinham mais de 60 anos. Essa realidade, porém, vem mudando numa velocidade assombrosa e para a qual não estamos preparados. (IBGE, 2003). O percentual de pessoas acima dessa faixa etária aumentou para $8,6 \%$ no ano de 2002 , e segundo expectativas a população idosa deverá representar $13 \%$ da população brasileira. (IBGE, 2003).

A população brasileira, por ter sido considerada jovem durante muito tempo, não se preocupou com a defesa da dignidade e do bem-estar dos idosos. (IBGE, 2003). Diante desses fatos, muitas famí-

* Alunos do 4ํano de Enfermagem. Faculdades Integradas Teresa D’ Ávila - Lorena - SP, Brasil.

** Doutoranda pelo Programa de Pós-Graduação em Enfermagem na Saúde do Adulto, da Escola de Enfermagem da Universidade de São Paulo. Professora titular das Faculdades Integradas Teresa D’ Ávila - Lorena - SP. Endereço para correspondência: Rua Oscar Mesquita, 161, Bairro Jd. Coelho Neto, CEP: 12514080 , Guaratinguetá - SP. E-mail: claudia-lysia@ig.com.br.

$\longrightarrow$ doi:10.5335/rbceh.2012.046 
lias, não tendo condições de ampará-los, acabam encaminhando-os à institucionalização. O idoso, nesse processo, passa por várias etapas, numa transformação rápida em que deixa sua casa, um ambiente familiar, para conviver com pessoas desconhecidas. (CALDAS, 2002; FLORIANI; SCHURAMM, 2004).

Considerando o aumento da população idosa tanto nos países desenvolvidos como nos que estão em desenvolvimento, cremos que um dos desafios sociais que se impõem seja o de enfrentar a velocidade desse aumento. $\mathrm{O}$ envelhecimento da população sofre uma influência importante da redução da taxa de fecundidade. Segundo Chaimowicz (1997), o Brasil passa por um processo de envelhecimento populacional rápido e intenso, como se pode observar desde o início do século.

De acordo com Augusto e Barbieri (2005), até 1980, o Brasil era considerado um país jovem. A pirâmide etária nacional era bem larga na base e afunilada no topo, significando que, naquele período, predominava uma população em idade de crescimento. Havia mais jovens do que adultos com mais de 40 anos. A partir daquela década, a forma da pirâmide mudou. A base sofreu uma contração, e, inversamente, a camada da população idosa apresentou sinais de crescimento, fato que predomina até hoje, caracterizando o Brasil, desde o início do século XXI, como um dos países de meia-idade.

Para Born "muitos idosos encaram o processo de institucionalização como perda de liberdade, abandono pelos filhos, aproximação da morte, além da ansiedade quanto à condução do tratamento pelos funcionários". (2002, p. 403). Um dos sentimentos mais presentes na vida do idoso institucionalizado é o de "exclusão", além de mágoa por ter sido abandonado e a crença de que é um peso para a família.

Quando passa a fazer parte do ambiente institucional, o idoso tem dificuldade de lidar com as perdas, tais como de status e de papéis sociais, tendo de enfrentar problemas de saúde e de ordem econômica, isolamento, rejeição, marginalização social, entre outras questões (TAVARES, 2007). Alguns sentem tensão, angústia, desespero, insegurança, e, quanto maior for o potencial para a perda desse vínculo, mais intensas e variadas serão essas reações, podendo vir a prejudicar o indivíduo. Muitos idosos sentem vergonha em dizer que foram internados involuntariamente, preferindo argumentar que a internação se deu devido a problemas de saúde ou por falta de condição da família, tentando esconder as ameaças sofridas pelos próprios familiares.

Assim, o objetivo deste estudo é conhecer o que o idoso sente, percebe e deseja diante da institucionalização.

\section{Método}

Trata-se de um estudo do tipo exploratório com análise quali-quantitativa. A pesquisa foi realizada em uma Instituição de Longa Permanência para Idosos (ILPI) de uma cidade do Médio Vale do Paraíba, no estado de São Paulo. Os dados foram coletados no mês de fevereiro de 2010. Participaram sujeitos com idade 
igual ou superior a 60 anos, residentes há pelo menos um ano na ILPI, lúcidos e capazes de responder coerentemente aos instrumentos de coleta de dados e que aceitaram participar como voluntários, assinando o Termo de Consentimento Livre e Esclarecido. Como critério de exclusão foi definido escore inferior a 18 pontos para o Mini-Exame do Estado Mental (MEEM). Este projeto foi encaminhado ao Comitê de Ética em Pesquisa das Faculdades Integradas Teresa d'Ávila (FATEA), sob o número 86/2009, e recebeu parecer favorável ao seu desenvolvimento.

\section{Resultados e discussão}

Dentre os idosos da ILPI que constituiu o campo de pesquisa, 42 atendiam aos critérios de inclusão do estudo. Entretanto, de acordo com os critérios de exclusão do MEEM, seguindo-se os pontos de corte propostos por Brucki et al. (2003), 28 idosos foram eliminados. A população foi constituída de 14 idosos (100\%), correspondendo a 33,3\% do total de idosos que atenderam aos critérios de inclusão.

$\mathrm{O}$ estudo caracterizou-se pelo predomínio do sexo feminino $(64,2 \%)$, de faixa etária entre 70 e 80 anos de idade $(35,7 \%)$ e de solteiros $(78,5 \%)$.

Araújo, Coutinho e Saldanha (2006), assim como Neri (2007) e Ferrari (2001), também observaram, em seus estudos, um predomínio do sexo feminino na instituição. Como tendência do país desde 1950, segundo Grossi e Souza (2003), as mulheres apresentam uma expectativa de vida elevada frente aos homens (vivem, em média, cinco anos a mais do que eles). Além disso, Chaimowicz e Greco (1999), ao estudarem a dinâmica da institucionalização de idosos em Belo Horizonte, constataram que esta parece ser em grande parte uma questão feminina, visto que as mulheres constituem $81,1 \%$ da população dos asilos. Assim, Dias (2007) afirma que existe um processo de "feminização da velhice".

Em relação à idade, verificamos que a maioria dos idosos encontrava-se na faixa de 70 a 80 anos (50\%), devendo-se ressaltar que as mulheres apresentaram faixa etária superior à dos homens. A média de idade foi de 73,3 anos e a mediana, 74 anos. Essa situação pode ser confirmada em pesquisa realizada pelo IBGE (2003), a qual evidenciou que a expectativa de vida da mulher brasileira é superior à dos homens, 75,5 contra 67,9 anos, embora a faixa etária média da amostra estudada tenha sido maior.

Na variável estado civil, 78,5\% dos idosos institucionalizados relataram ser solteiros. Neri (2007), em seu estudo, verificou que a maior proporção de pessoas solteiras e viúvas, assim como o fato de, em geral, não terem o suporte dos filhos, talvez possa ser uma das causas da institucionalização desses idosos.

Dez idosos $(71,4 \%)$ relataram não ter filhos, e quatro disseram ter. Paschoal (2006) ressalta que morar sozinho, não ter filhos ou não estar casado são fatores de risco para a institucionalização de idosos.

Quanto à escolaridade, observamos que $57,1 \%$ dos idosos apresentavam escolaridade correspondente ao antigo 
primeiro grau completo (até oito anos). Davim e colaboradores (2004), igualmente, encontraram, em seu estudo realizado em três instituições asilares na cidade de Natal (RN), baixo nível de escolaridade, visto que $46 \%$ dos idosos pesquisados não eram alfabetizados, e 0 restante tinha apenas o primeiro grau concluído. Especificamente em Florianópolis, um panorama da população idosa da cidade revela que há $8,4 \%$ de idosos vivendo na capital, dos quais $11,9 \%$ possuem nível superior e $14,3 \%$ são analfabetos. (CARDOSO, 2006). De acordo com Merlotti, Casara e Cortelletti (2004), a situação de analfabetismo ou de semialfabetização compromete o nível de entendimento das pessoas. Além disso, a escolaridade dos participantes mostra que, no passado, estudar era privilégio de poucos.

Dos idosos entrevistados, $85,7 \%$ declararam ser católicos. Verifica-se que a prática de uma religião pelo idoso permite-lhe estabelecer um elo entre as limitações e o aproveitamento de suas potencialidades ou, quando isso não ocorre, ajuda-o a vencer com mais facilidade essa última etapa da vida. (ARAÚJO, 1999). Para Valente (2000), a finalidade da religião é o conforto moral e a preservação dos valores espirituais do ser humano, que desmistifica a morte e revela a imortalidade da alma. Conforme Goldstein e Sommerhalder (2002), a religião pode prover um significado à vida, trazendo-lhe sentido, de forma a transcender o sofrimento, a sensação de perda, a proximidade da morte.

Quanto à naturalidade, oito idosos $(57,1 \%)$ eram da mesma cidade onde foi realizada a pesquisa; outros três $(21,4 \%)$, de cidades próximas, até um raio de aproximadamente $200 \mathrm{~km}$; e os demais $(21,4 \%)$ provinham de outros estados.

Quanto ao item moradia antes da institucionalização, 85,7\% dos idosos relataram residir com familiares. Araújo e Ceolim (2003) também verificaram, em seus estudos, que a maioria dos idosos residia com familiares, incluindo nessa categoria irmão, família de irmão, filhos e família de filhos. Como ressaltam Araújo e Ceolim (2008), ficar viúvo ou morar sozinho é um acontecimento esperado nessa fase da vida.

Sobre os motivos que os levaram a residir na instituição, $64,2 \%$ responderam o fato de terem ficado sozinhos, e o restante pelo fator financeiro e por doença. Este fator também foi observado em pesquisa por Araújo, Coutinho e Saldanha (2006), além da perda por morte, da pessoa com quem o idoso residia anteriormente, quer seja de familiar, cônjuge ou empregador, e problemas relacionados à moradia anterior. De acordo com Caldas (2002), outros fatores podem levar à institucionalização dos idosos, como a solidão por não terem família, o celibatismo, a viuvez e o fato de não terem filhos, ou, quando os têm, por estes residirem distantes, por falta de recursos financeiros para prover o cuidado adequado etc.

Quanto ao tempo de institucionalização, o estudo mostrou que dez idosos $(71,4 \%)$ apresentavam de um a dez anos de institucionalização. Em estudo, Araújo, Coutinho e Saldanha (2006) verificaram que a média de institucionalização para homens era de 8,2 anos, 
enquanto, para mulheres, era de 11,8 anos. Monteiro et al. (2001) constataram que cinco deles estavam há menos de dois anos, dois entre cinco e sete anos, e dois há mais de treze anos. Ramalheira (2006), em seu estudo com idosos institucionalizados, na cidade de Campinas - SP, observou o tempo de permanência média de 120 meses (dez anos). Silva et al. (2005), ao realizarem uma pesquisa numa ILPI em Belo Horizonte, verificaram um tempo médio de permanência no asilo por parte dos idosos de 7,7 anos, chegando a observar idosos internos há 26 anos. Oliveira et al. (2006) também notaram, em sua pesquisa, que $12,12 \%$ dos idosos permaneciam institucionalizados há mais de dez anos.

No que diz respeito ao relacionamento familiar, nove idosos $(64,2 \%)$ relataram que este era positivo, três $(21,4 \%)$ o consideravam ótimo, e dois idosos (14,2\%), regulares. Dias (2007) verificou que $45,5 \%$ dos idosos afirmaram que tinham um bom relacionamento com a família antes da institucionalização, mas pôde constatar que, na realidade, isso não se confirmava, uma vez que houve abandono dos idosos em 63,6\% dos casos, com a imposição da institucionalização pela família. Quanto à satisfação em morar com os familiares, onze idosos $(78,5 \%)$ estavam satisfeitos, o que consta, também, em estudo de Dias (2007), de acordo com o qual $63,63 \%$ dos idosos estavam satisfeitos com a moradia anterior. A satisfação foi justificada, principalmente, pela convivência familiar, pela liberdade proporcionada a quem vive sozinho, pelo sentimento de pertencimento e/ou propriedade em relação à casa em que se vive. Destes, $36,37 \%$ não quiseram explicar o motivo da satisfação. De acordo com Licht (2007), em se tratando dos idosos, a casa inclui um significado de abrigo, de proteção e de conquista e memória afetivas que foram construídas ao longo de toda a vida, e é por si só motivadora de satisfação nesse grupo etário. Seis idosos $(42,8 \%)$ relataram receber visita familiar, e oito idosos $(57,1 \%)$ não a recebem. Cortelleti, Casara e Herédia (2004) afirmam que a institucionalização leva o idoso a substituir suas representações sociais por novas, que se caracterizam pela perda do convívio familiar e pelo rompimento com vínculos afetivos.

Perguntados sobre a satisfação com a instituição em que residem, 13 idosos $(92,8 \%)$ declararam estar satisfeitos, e quanto aos serviços a eles prestados, dez idosos $(71,4 \%)$ o consideraram bom. A maioria dos idosos institucionalizados, entrevistados por Davim (2004) e demais pesquisadores, também afirmaram sentir-se bem nas instituições onde residem e afirmaram que não desejariam sair do convívio asilar, justificando gostarem de morar no local, não terem para onde ir, serem muito velhos e não haver ninguém que os acolha. Nesse sentido, apesar de o ambiente institucional ser distante de um ambiente familiar, os participantes do estudo o veem como um lugar agradável e preferem viver ali a viverem sozinhos.

$\mathrm{Na}$ questão que investigava quem tomou a iniciativa de institucionalizá-los, quatro idosos $(28,5 \%)$ relataram ter sido por vontade própria; cinco idosos $(35,7 \%)$ admitiram terem sido os fami- 
liares; outros cinco (35,7\%), os amigos; e o restante, familiares e amigos, sem que houvesse lhe sido dada oportunidade de escolha. Alcântara (2004) afirma que a decisão da institucionalização por parte da família pode ser mal interpretada pelos idosos, levando a possíveis mágoas. $\mathrm{O}$ que se pode compreender é que, na verdade, a perda da autonomia do idoso em decidir-se pela institucionalização, positiva ou negativamente, gera insatisfações e que a imposição ao idoso em relação ao asilamento é interpretada da maneira correta, como um desrespeito ao direito de escolha. Dias (2007), em pesquisa, ao questionar os idosos sobre a pessoa que tomou a decisão quanto ao asilamento, percebeu que a maioria deles foi levada à instituição pela própria família, correspondendo a $72,7 \%$ dessa população.

A avaliação cognitiva, de acordo com o MEEM, mostrou uma variação entre 18 a 28 pontos. Cinco $(35,7 \%)$ atingiram 18 pontos, quatro $(28,5 \%)$ alcançaram entre 19 e 22 pontos, outros quatro idosos $(28,5 \%)$, entre 23 e 24 pontos, e um idoso $(7,14 \%)$ atingiu 28 pontos. A pontuação média foi de 21 pontos, e a mediana, de 21 pontos.

Dando sequência à pesquisa, os idosos responderam às questões sobre seus sentimentos. Na categoria "institucionalização", relataram que a instituição é hoje a sua casa e que os residentes são sua família, por não haver outra opção. Contribuem para essa reflexão Bastiani e Santos (2000), em cuja obra afirmam que, atualmente, grande parte dos indivíduos que constituem a terceira idade perdeu muito do poder que outrora exer- cia, chegando a abdicar, em muitos casos, também dos ideais pelos quais lutaram toda uma vida, o que pode levá-los, efetivamente, a uma situação de abandono. "Por enquanto é minha casa, até eu voltar para minha casa de verdade. $\mathrm{E}$ os membros são como se fosse minha família. Sinto. Porque não tenho pai e nem mãe, e são eles aqui que cuidam de mim. Minha família é aqui mesmo. Não sinto, não. A gente viveu e nasceu na casa da gente."

Na categoria "sentimentos", alguns citaram saudade, alegria, abandono, tristeza, gratidão, perda, vazio, satisfação, enquanto outros preferiram não se pronunciar. Para Dias (2007), o sentimento de abandono é comum nos idosos, principalmente pelo fato de que a velhice leva a comprometimentos físicos e mentais, causando-lhes sensação de impotência diante das atividades do próprio cotidiano. Segundo Malkinson e Bar-Tur (apud Haddad, 2008), as perdas não são representadas somente pela morte em si, mas também por diversas "pequenas mortes" ao longo das fases evolutivas, perda do emprego, da posição social, de residências, entre outras, incluindo as relacionadas aos papéis que devem ser abandonados no decorrer da infância, da adolescência, da vida adulta e da velhice. Conforme Silva et al. (2005), quando são estabelecidos vínculos afetivos entre pessoas idosas, estas se sentem mais fortalecidas para enfrentar a tristeza. Sentimentos como dor, ansiedade e preocupação são compartilhados entre os que estão institucionalizados. "Queria andar, ter família, sinto falta dos meus 
filhos, da minha casa. Tudo é bom, só tenho alegria, não tenho tristeza, não. Sinto saudades das minhas irmãs (elas já morreram). O único sentimento é de ter perdido minha família".

$\mathrm{Na}$ categoria "pessoa mais importante da sua vida", Deus foi citado com maior recorrência, seguido dos membros familiares e amigos. Alcântara (2004) explica a concentração de atividades religiosas, afirmando que a velhice compreende melhor o sentido da vida humana, porque a espiritualidade se aguça nesse período da existência, fazendo que as pessoas busquem mais a Deus e as práticas religiosas e, consequentemente, vivam com mais qualidade de vida, resultado da aceitação das dificuldades vivenciadas. "A pessoa mais importante pra mim é Deus. Pessoa importante: a única que foi importante era minha mãe. Minha madrinha, que trabalha aqui na instituição. Deus, porque ele é o criador e os amigos, porque tem que se divertir, o dinheiro só traz infelicidade".

$\mathrm{Na}$ categoria "relacionamento familiar", como já expusemos, muitos relataram ser boa, no entanto, nota-se que muitos não recebem visita de seus familiares. Araújo, Coutinho e Saldanha (2006) expõem que o papel da família é fundamental para que o idoso sinta-se amparado, e não marginalizado. O desaparecimento desses laços traduz-se em limitação da capacidade de movimento e em deterioração do seu estado moral e de saúde. Complementam Bastiani e Santos (2000) que a família continua sendo o centro da vida dos idosos, pois é ela quem transmite ao velho o sentimento de ser aceito, amado e útil, além da força necessária para lutar no dia a dia por uma vida digna. Entretanto, nem todos têm a sorte de possuir uma família equilibrada e acolhedora. "Meus filhos aparecem de vez em quando aqui por causa do trabalho, e às vezes eu ligo pra eles. Ninguém vem me visitar. Apenas aparecem uns amigos e conhecidos. Tinha um bom relacionamento, mas agora ninguém vem mais nem me visitar. Não tenho contato mais com minha família".

Na categoria "descontentamento", os idosos relataram não haver, e outros mencionaram somente a impossibilidade de sair. Quanto aos valores positivos da instituição, listaram comida, carinho, lugar, funcionários e o fato de não faltar nada. Para Mazza e Lefêvre (2004), os asilos são importantes porque se tornam um lugar seguro para o idoso, provendo-o de proteção e cuidado. Cortelleti, Casara e Herédia (2004) avaliam que os asilos têm como aspecto negativo a tendência de não oferecerem individualidade, independência, personalização e autonomia aos internos. Aspectos positivos são mencionados por Bastiani e Santos (2000). Os autores relatam que, para alguns idosos, a institucionalização parece devolver um pouco de alegria, pois se sentem menos isolados, têm amizades, são bem cuidados, alimentam-se adequadamente e possuem seus objetos próprios. "Não tenho nada de negativo; positivos, comida, amigos aqui. Negativo é não poder sair daqui, positivo tratam a gente bem, aqui não falta nada, comida, remédio etc. Aqui pra mim tudo é bom, positivo, a comida, os empregados, tudo é bom." 
Na categoria "desejos", houve entre as respostas vontade de voltar a morar com a família, voltar para casa, poder andar, ter mais saúde. Martins (2002) destaca que muitos fenômenos do envelhecimento e da velhice são considerados pelas restritas modificações que ocorrem na dimensão física, porém, devem ser igualmente reconhecidas as mudanças na forma de pensar, de sentir e de agir dos seres humanos que vivenciam essa etapa do desenvolvimento. "Voltaria a morar com meu filho. Queria andar, ter família, filhos e casa. Não mudaria nada, minha vida está ótima aqui, pois eu quero sossego. Mudaria a saúde, para poder me divertir, dançar, curtir a vida. Gosto da instituição, sinto alegre, mas queria sair em pouco, passear."

Por fim, a categoria "continuar vivendo na instituição ou outro desejo", todos manifestaram o anseio de voltar para casa, para a família. Apesar do aumento expressivo das institucionalizações, reconhecemos que viver em um asilo pode até oferecer possibilidade de acolhimento e de expressão das pessoas, mas não é o mesmo que viver em uma família, onde os laços do passado e do presente estão vivos e são compartilhados afetiva e socialmente. (SANTINI, 2000; FERREIRA, 2003; BULLA; MEDIONDO, 2004).

\section{Conclusão}

Ao analisarmos as perspectivas dos idosos, verificamos que alguns gostariam de mudar-se da instituição, revelando, assim, a inexistência de um sentimento de pertencimento e identificação em relação ao lugar. Os idosos demonstra- ram falta de expectativa em relação à instituição e desejo de mudanças na vida pessoal. Em relação à sua autoavaliação quanto à dependência/independência, observamos um sentimento de frustração, por alguns serem independentes, e estarem institucionalizados.

A questão da institucionalização, na forma como é feita e vivenciada pelos idosos, causa-lhes o anseio de serem esquecidos, rejeitados, desamparados pela família e pela sociedade, chegando a levá-los, em casos mais sérios, a uma depressão profunda.

Neste estudo, constatamos que alguns idosos percebem a ILPI como um lar, outros a consideram apenas como um local de moradia destinado a cuidar de indivíduos doentes. Também verificamos que os idosos consideram os demais residentes e trabalhadores como conhecidos e, em poucos casos, como amigos e família.

Institutionalized elderly: what you feel, and want to realize?

\section{Abstract}

This work is a reality that is emerging, the elderly before the institutionalization process goes through several stages, leaves home and goes to live with rules, a new place with unfamiliar people. The aim of this study was to identify what this old feels, perceives and wants before all these changes, show the feelings that surround this old. Observed a predominance of elderly female, between 70-80 years old, single, and the reasons that led them to be alone. The present study reports the seniors on this institutionalization process, which allows some considerations that despite 
so much technology and evolution, there is still a group of people without support from society and family, who want to live, be happy, have feelings, desires, realize that your space decreases and no alternative left the institution.

Keywords: Elderly. Long-Stay Institution for the Elderly. Feeling.

\section{Referências}

ALCÂNTARA, A. O. Velhos institucionalizados e família: entre abafos e desabafos. Campinas, SP: Alínea, 2004.

ARAÚJO, C. D. S. F. Aspectos religiosos do idoso. In: PETROIANO, A.; PIMENTA, L. G. Clínica e cirurgia geriátrica. Rio de Janeiro: Guanabara, 1999. p. 8-9.

ARAÚJO, C. L. O.; CEOLIM, M. F. Qualidade do sono do idoso residente em instituição de longa permanência. 2008. 135 f. Dissertação (Mestrado em Enfermagem) - Departamento de Enfermagem, Universidade Estadual de Campinas, Campinas, SP, 2008.

ARAÚJO, L. F.; COUTINHO, M. P. L.; SALDANHA, A. A. W. Análise comparativa das representações sociais da velhice entre idosos das instituições geriátricas e grupos de convivência. Psicologia \& Sociedade, Porto Alegre, v. 18, n. 2, maio/ago. 2006.

ARAÚJO, M. O. P. H.; CEOLIM, M. F. O $O u$ tocuidado em idosos independentes residentes em instituições de longa permanência. 2003. 85 f. Dissertação (Mestrado em Enfermagem) Departamento de Enfermagem, Universidade Estadual de Campinas, Campinas, SP, 2003.

BASTIANI, F.; SANTOS, I. S. Sentimentos despertados nos idosos internados em casas asilares. Disciplinarum Scientia Série: Ciência Biologia e da Saúde, Santa Maria, v. 1, n. 1, p. 113-124, 2000.
BORN, T. Cuidado ao idoso em instituição. In: PAPALÉO NETO, M. et al. (Orgs.). Gerontologia. São Paulo: Atheneu; 2002. p. 403-413.

BRUCKI, S. M. D. et al. Sugestões para o uso do Mini-Exame do Estado Mental no Brasil. Arquivo Neuropsiquiatria, v. 61, p. 777-781, 2003.

BULLA, L. C.; MEDIONDO, Z. M. Velhice, dependência e vida cotidiana institucional. In: CORTELLETI, I. A.; CASARA, M. B.; HEREDIA, V. B. M. (Orgs.). Idoso asilado: um estudo gerontológico. Porto Alegre: EdiPUCRS, 2004. p. 87-97.

CALDAS, C. P. Contribuindo para a construção da rede de cuidados: trabalhando com a família do idoso portador de síndrome demencial. Textos Envelhecimento, Rio de Janeiro, v. 4, n. 8, p. 39-56, 2002.

CARDOSO, V. S. "Tudo que eu fiz eu não tenho nada que me arrepender": percepções e vivências do estágio tardio na perspectiva de casais idosos. 2006. 212 f. Dissertação (Mestrado em Psicologia) - Programa de Pós-Graduação em Psicologia, Universidade Federal de Santa Catarina, Florianópolis, 2006.

CHAIMOWICZ, F. A saúde dos idosos brasileiros às vésperas do século XXI: problemas, projeções e alternativas. Revista Saúde Pública, São Paulo, v. 31, n. 2, p. 193, 1997.

CHAIMOWICZ, F.; GRECO, D. B. Dinâmica da institucionalização de idosos em Belo Horizonte, Brasil. Revista Saúde Pública, São Paulo, v. 33, n. 5, out. 1999.

CORTELLETI, I. A.; CASARA, M. B.; HERÉDIA, V. B. M. Idoso asilado: um estudo gerontológico. Caxias do Sul, RS: EDUCS/ EdiPUCRS, 2004.

DAVIM, R. M. et al. Estudo com idosos de instituições asilares no município de Natal/RN: características socioeconômicas e de saúde. Revista Latino-Americana de Enfermagem, Ribeirão Preto, v. 12, n. 3, 2004. 
DIAS, I. G. A institucionalização asilar na percepção do idoso e sua família: estudo do "lar dos velhinhos". 2007. 57 f. Dissertação (Mestrado em Economia Doméstica) - Universidade Federal de Viçosa, Viçosa, MG, 2007.

FERRARI, M. A. C. Instituições que abrigam idosos: proposta de padrões mínimos para seu funcionamento. Revista de Terapia Ocupacional, v. 2, n. 2/3, p. 86-99, jun./set. 2001.

FERREIRA, M. L. M. Memória e velhice: do lugar da lembrança. In. BARROS, M. M. L. (Org.). Velhice ou terceira idade? Estudos antropológicos sobre identidade, memória e política. 3. ed. Rio de Janeiro: Editora FGV, 2003. p. 115-117.

FLORIANI, C. A.; SCHURAMM, F. R. Atendimento domiciliar ao idoso: problema ou solidão? Caderno Saúde Pública. Rio de Janeiro, v. 20, n. 4, july/aug. 2004.

GOLDSTEIN, L. L.; SOMMERHALDER, C. Religiosidade, espiritualidade e significado existencial na vida adulta e velhice. In: FREITAS, E. V. et al. (Orgs.). Tratado de geriatria e gerontologia. Rio de Janeiro: Guanabara Koogan, 2002. p. 918-950.

GROSSI, P. K.; SOUZA, M. R. Os idosos e a violência invisibilizada na família. Revista Virtual Textos \& Contextos, Porto Alegre, v. 2, n. 2, p. 1-14, dez. 2003.

HADDAD, D. F. (Org.). Vivências de perdas e lutos de idosos residentes em uma instituição asilar de longa permanência em Ribeirão Preto - SP, 2008. 142 f. Dissertação de Mestrado, Escola de Enfermagem de Ribeirão Preto - SP, USP, 2008.

INSTITUTO BRASILEIRO DE GEOGRAFIA E ESTATÍSTICA(IBGE). Expectativa de Vida, 2003. Disponível em: <http://www.ibge. gov.br>. Acesso em: 10 jan. 2012.

LICHT, F. B. Idosos, cidade e moradia: acolhimento ou confinamento? Revista Kairós, São Paulo, v. 5, n. 2, p. 67-80, dez. 2007.
MARTINS, C. R. M. O envelhecimento segundo adolescentes, adultos e idosos usuários do SESC Maringá: um estudo de representações sociais. 2002. 168 f. Dissertação (Mestrado em Psicologia) - Departamento de Psicologia, Universidade Federal de Santa Catarina, Florianópolis, 2002.

MAZZA, M. M. P. R.; LEFÊVRE, F. A. A institucionalização asilar segundo o cuidador do idoso. Saúde e Sociedade, São Paulo, v. 13, n. 3, p. 68-77, set./dez. 2004.

MERLOTTI, V. B. H.; CASARA, M. B.; CORTELLETTI, I. A realidade do idoso institucionalizado. Textos Envelhecimento, v. 7, n. 2, p. 9-31, 2004.

MONTEIRO, E. M. L. M. et al. Vivenciando o envelhecimento: percepção do idoso institucionalizado. Nursing, São Paulo, v. 4, n. 38, p. $20-24$, jul. 2001

NÉRI, A. L. (Org.). Qualidade de vida na velhice: enfoque multidisciplinar. Campinas, SP: Alínea, 2007.

OLIVEIRA, C. R. M. et al. Idoso e família: asilo ou casa. O Portal dos Psicólogos, p. 1-12. 2006. Disponível em: <http://www.psicologia. com.pt>. Acesso em: 20 abr. 2011.

PASCHOAL, S. M. P. Epidemiologia do envelhecimento. In: PAPALÉO NETTO, M. et al. (Orgs.). Gerontologia. São Paulo: Atheneu, 2006. p. 26-43.

RAMALHEIRA, R. M. F. Incidência de síndrome gripal e eventos adversos à vacinação contra influenza em idosos institucionalizados no município de Campinas - São Paulo. 2006. 185 f. Dissertação (Mestrado) - Universidade Estadual de Campinas, Campinas, SP, 2006.

SANTINI, R. E. O perfil do idoso na sua unidade doméstica: o caso de Viçosa - MG. 2000. $173 \mathrm{f}$. Dissertação (Mestrado em Economia Doméstica) - Universidade Federal de Viçosa, Viçosa, 2000. 
SILVA, A. E. C. et al. Aspectos bio-psico-sociais dos idosos institucionalizados na Casa do Ancião da Cidade Ozanan, no ano de 2005, em Belo Horizonte. In: ENCONTRO DE EXTENSÃO DA UFMG, 8, 2005, Belo Horizonte. Anais... Belo Horizonte: UFMG, 2005.

TAVARES, L. Estimulação em idosos institucionalizados: efeitos da prática de atividades cognitivas e atividades físicas. 2007. $215 \mathrm{f}$. Dissertação de (Mestrado em Psicologia) Universidade Federal de Santa Catarina, Florianópolis, 2007.

VALENTE, M. A. Espiritualidade: sua importância domiciliária. In: DUARTE, Y. A. O. (Org.). Atendimento domiciliar: um enfoque gerontológico. São Paulo: Atheneu, 2000. p. 592-598. 